Case Reports in Neurology
Case Rep Neurol 2020;12:15-21

DOI: $10.1159 / 000501820$

Published online: December 14, 2020
(C) 2020 The Author(s)

Published by S. Karger AG, Basel www.karger.com/crn

This article is licensed under the Creative Commons Attribution-NonCommercial 4.0 International License (CC BY-NC) (http://www.karger.com/Services/OpenAccessLicense). Usage and distribution for commercial purposes requires written permission.

\title{
Acute Ischaemic Stroke Successfully Treated with Thrombolytic Therapy and Endovascular Thrombectomy with Non-Contrast Computed Tomography and Computed Tomography Angiogram Protocol
}

\author{
Tsun-Haw Toh Khairul Azmi Abdul Kadir Mei-Ling Sharon Tai \\ Kay Sin Tan \\ Division of Neurology, Faculty of Medicine, University of Malaya, Kuala Lumpur, Malaysia
}

\section{Keywords}

Mechanical thrombectomy - Non-contrast computed tomography · Computed tomography angiogram · Alberta Stroke Programme Early Computed Tomography Score

\begin{abstract}
Early endovascular thrombectomy leads to improved outcomes for patients with proximal occlusions when started within $6 \mathrm{~h}$ from onset of symptoms. We present a case illustrating the flow of events for a patient who underwent endovascular thrombectomy in our centre after conventional imaging - a brain non-contrast computed tomography (NCCT) and CT angiogram (CTA) - achieving a door-to-groin time of $195 \mathrm{~min}$. The patient is a 65-year-old who presented with signs and symptoms of a left middle cerebral artery (MCA) territory infarct. His National Institute of Health Stroke Scale (NIHSS) score was 15 on presentation and his brain NCCT showed an Alberta Stroke Programme Early CT Score (ASPECTS) of 8. His CTA showed a left MCA distal M1 occlusion with focal calcification and stenosis of the proximal left internal carotid artery. He was subsequently thrombosed and underwent thrombectomy successfully, with a door-to-groin-puncture time of $195 \mathrm{~min}$. A TICl $2 \mathrm{~b}$ reperfusion was achieved. His NIHSS
\end{abstract}

Tsun-Haw Toh or Kay Sin Tan
Department of Neurology
University of Malaya
Lembah Pantai, Kuala Lumpur 59100 (Malaysia)
tohtsunhaw@icloud.com or tanks@ummc.edu.my




\section{Case Reports in Neurology}

Case Rep Neurol 2020;12:15-21

DOI: 10.1159/000501820

(c) 2020 The Author(s). Published by S. Karger AG, Basel www.karger.com/crn

Toh et al.: Acute Stroke Thrombectomy with NCCT and CTA

score improved to 9 over the next 2 days. For cases with straightforward NCCT and CTA with no contraindications, endovascular thrombectomy should be pursued without delay. A review of the current available literature for the usage of NCCT and CTA as well as the importance of ASPECTS scoring in patient selection for endovascular thrombectomy was included.

(C) 2020 The Author(s)

Published by S. Karger AG, Basel

\section{Introduction}

In recent years, significant evidence has surfaced to emphasize the beneficial effects of endovascular thrombectomy (EVT) for the treatment of acute ischaemic stroke due to large vessel occlusion, with time from stroke onset $<6 \mathrm{~h}$ all the way up to $24 \mathrm{~h}$ in selected patients. For stroke patients presenting early within the intervention window, the decision to proceed to EVT should be rapid, aiming for fast revascularization. Early EVT leads to improved outcomes for patients with proximal occlusions when started within $6 \mathrm{~h}$ from onset of symptoms [1]. We present a case illustrating the flow of events for a patient who underwent EVT in our centre with conventional imaging, which included brain non-contrast computed tomography (NCCT) and CT angiogram (CTA), achieving an onset to recanalization time of approximately $5 \mathrm{~h}$.

\section{Case Report}

The patient is a 65-year-old gentleman, an ex-smoker who had had diabetes mellitus type 2 and hypertension for more than 10 years. His symptoms started at 7:45 p.m. with drooling of saliva and stammered speech, followed by right-sided body weakness and difficulty in speech production. Upon arrival to the Emergency Department of the University Malaya Medical Centre at 9 p.m., he was assessed by our neurology team, revealing a blood pressure of $150 / 75 \mathrm{~mm} \mathrm{Hg}$ with a capillary sugar level of $7.7 \mathrm{mmol} / \mathrm{L}$. His National Institute of Health Stroke Scale (NIHSS) score at that time was 15, with right-sided body weakness, expressive aphasia and neglect. There were no carotid bruit or cardiac murmurs detected. The electrocardiogram showed sinus rhythm with no arrythmia.

A brain CT showed an Alberta Stroke Programme Early CT Score (ASPECTS) of 8 with hypodensities on M4 and M6 areas. A CTA showed complete occlusion of the left distal M1 with increased collateral over the left M2 territory (Fig. 1). He was subsequently thrombosed with intravenous alteplase at 10:02 p.m., with a door-to-needle time of $62 \mathrm{~min}$. The interventional radiologist was informed regarding the case midway through the thrombolysis and the decision for mechanical thrombectomy was made. His NIHSS score was 13 upon the completion of thrombolysis and he was pushed to the procedure room for cerebral angiogram. With the aid of the Terumo guide wire and a 5-Fr-long vertebral catheter, an angiogram of bilateral internal carotid arteries (ICAs) was performed showing a left distal M1 complete occlusion with collaterals seen from the left anterior and posterior cerebral artery (PCA) (Fig. 2). Using a Transcend 0.014-inch guidewire, Marksman catheter, Flowgate $8 \mathrm{Fr} \times 9 \mathrm{~cm}$ balloon and a SOLITAIRE retriever, percutaneous balloon-assisted aspiration thrombectomy of the left middle cerebral artery (MCA) was performed successfully, showing thrombolysis in cerebral infarction (TICI) $2 \mathrm{~b}$ reperfusion of the left MCA at 12:50 a.m. The door-to-groin-puncture time

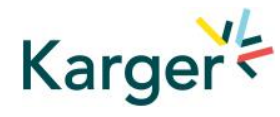




\section{Case Reports in Neurology}

Case Rep Neurol 2020;12:15-21

\begin{tabular}{l|l}
\hline DOI: $10.1159 / 000501820$ & (c) 2020 The Author(s). Published by S. Karger AG, Basel
\end{tabular} www.karger.com/crn

Toh et al.: Acute Stroke Thrombectomy with NCCT and CTA

was $195 \mathrm{~min}$ and onset-to-recanalization time was $305 \mathrm{~min}$. The procedure was uneventful, and the patient subsequently improved further with an NIHSS score of 9 over the next 2 days. The repeat CT of the brain showed a frontotemporal infarct with a small haemorrhagic transformation.

\section{Discussion}

For eligible stroke patients with straightforward NCCT, CTA and no contraindications, EVT should be pursued without delay. The case here is an example of a patient who presented early and the decision for EVT was made solely based on the timing from onset and simple imaging modalities, namely NCCT with ASPECTS and CTA showing large vessel occlusion. Many large-scale trials for EVT were released over the recent years, two of which, MR CLEAN [2] and ReVASCAT [3], have shown that it is safe to perform EVT with basic imaging modalities such as NCCT and CTA. These studies recruited patients within 6 and $8 \mathrm{~h}$ after stroke onset, respectively, and were able to obtain a $13.5-15.5 \%$ increase in patients achieving a better functional outcome with no significant increase in intracranial haemorrhage. These trials justify the need to further study the possibility of selecting patients for EVT using simpler imaging techniques. Not only does this approach reduce the time to revascularization, it is also much more readily available and accessible. It may allow a significant reduction in the timeto-groin puncture by bypassing more complex and time-consuming imaging methods [4].

Current guidelines recommend that patients with large vessel occlusion demonstrated on imaging undergo EVT as soon as possible within $6 \mathrm{~h}[5,6]$. The association between rapid recanalization and better patient outcome is well established. The phrase "Time is brain" strongly emphasizes the concept where neuronal death occurs with every second of delay in the race to reperfusion in acute stroke. Not only that, the proportion of patients eligible for recanalization also declines over time. Post hoc analysis of the Interventional Management of Stroke (IMS) III trial and the Solitaire FR Thrombectomy for Acute Revascularization (STAR) trial has proven that achieving faster reperfusion is associated with a better functional outcome $[7,8]$. The dependence of good clinical outcomes on the speed of reperfusion has been emphasized in the HERMES time-to-treatment meta-analysis, and for every hour of reperfusion delay, the absolute risk difference for chances of a good outcome is reduced by $6.7 \%$ [1]. A similar trend was also seen in the DAWN trial where the likelihood of achieving a modified Rankin Score of 0-2 at 90 days declined with time since last known normal [9].

When using only NCCT and CTA to decide on EVT, the ASPECTS is invaluable to give an estimate on the amount of salvageable brain tissue. Previous studies suggest that ASPECTS in NCCT may be safely used to select ischaemic stroke patients for EVT [10]. The inter-rater reliability in the analysis of early ischaemic changes in NCCT using ASPECTS is good across the entire scale with most inter-rater differences being within 1-2 points and it has also been shown to improve with increasing time from stroke symptom onset [11]. However, the agreement value drops to moderate for ASPECTS dichotomized at 7 for treatment selection [11]. The cut-off number for salvageable ASPECTS in considering EVT is still under much debate. Both the AHA and Australian Clinical Guideline for Stroke uses the ASPECTS cut-off of 6 and above $[5,6]$. A recent study, however, has shown that even in patients with large vessel occlusion and initial low ASPECTS $(\leq 5)$, vessel recanalization was associated with favourable effects on clinical endpoints with a decreased rate of malignant infarctions and an improved

\section{Karger'=}




\section{Case Reports in Neurology}

Case Rep Neurol 2020;12:15-21

DOI: $10.1159 / 000501820$

(c) 2020 The Author(s). Published by S. Karger AG, Basel www.karger.com/crn

Toh et al.: Acute Stroke Thrombectomy with NCCT and CTA

modified Rankin Score [12]. Whether or not the recommended ASPECTS for thrombectomy would be adjusted again in the future, only time will tell.

Previous studies have shown that more advanced and multimodal imaging such as CT perfusion or MRI causes significant delay in time to reperfusion compared to NCCT, with no difference in clinical outcomes, haemorrhage rates, or final infarct volumes [4]. Furthermore, the increased time spent in the selection process may lower the beneficial effects of reperfusion, especially for those with poor collaterals who will benefit the most from the fast timing. Hence for patients without contraindication for EVT, a NCCT and CTA should be used to select patients to save precious minutes in reperfusion. Only if uncertainties are present from conventional imaging would a perfusion scan undoubtedly be helpful to enable more patients who will otherwise be excluded to receive reperfusion therapy.

The vessel occlusion for our patient was in distal M1 of the left MCA. Current guidelines recommend EVT in M1 occlusions and extend the recommendation to M2/M3 in selected cases [5].

The devices used in the EVT in this case included stent retriever as well as aspiration pump. Stent retrievers combines 2 mechanisms of action, namely restoring blood flow with deployment and retrieval of clot using mesh [13]. Stent retrievers, however, have their potential drawbacks including anterior cerebral artery emboli (when treating middle cerebral artery or internal carotid artery occlusions), vessel wall damage, and challenges associated with tortuous aortic arches, cervical, or intracranial arteries [13]. Application of aspiration pump or vacuum syringe during retrieval of the stent has been performed in most case series with the benefit of reducing the number of distal emboli and increasing the amount of clot harvested [13].

Another consideration for this case we presented would be the possibility of going for primary thrombectomy without thrombolysis. Currently it is still unclear if intravenous thrombolysis before EVT gives additional benefits and this question will be assessed in two upcoming randomized-controlled studies (SWIFT DIRECT, MR CLEAN NO IV) [14]. The arguments for pre-EVT thrombolysis include higher reperfusion rates with fewer passes [15], theoretical thrombus softening and reperfusion of distal occlusion after EVT. Furthermore, the rates for reperfusion after intravenous thrombolysis alone is also substantial, ranging from 13 to $52 \%$ depending on the artery involved [16]. On the other hand, arguments against pre-EVT thrombolysis include the potential increase in rate of intracranial haemorrhage and thrombus migration [14]. As conclusive evidence is still unavailable, current guidelines recommend that patients eligible for IV alteplase should receive IV alteplase even if EVT is being considered, with neither treatment delaying the other $[5,6]$.

There is increasing evidence for the usage of NCCT and CTA-based imaging protocols for EVT selection, not only in those less than $6 \mathrm{~h}$, but also in those with late presentation or even wake-up strokes [17]. EVT was found to have similar rates of successful recanalization, intracranial haemorrhage, favourable 3-month outcome, and 3-month mortality in patients beyond $6 \mathrm{~h}$ from last seen well, selected based on NCCT and CTA when compared to those $<6 \mathrm{~h}$ [17]. This again reiterates the beauty of simple imaging modalities to select cases for EVT. Given the overall benefit and influence of time to treatment on outcome, it is important to simplify the imaging modalities used for patient selection in order to achieve a better time to reperfusion.

\section{Karger'=}




\section{Case Reports in Neurology}

\section{Statement of Ethics}

The authors have no ethical conflicts to declare.

\section{Conflict of Interest Statement}

The authors declare that there is no other potential conflict of interest regarding the publication of this paper.

\section{Funding Sources}

None.

\section{Author Contributions}

Tsun-Haw Toh: acquisition, interpretation of data for the work, drafting, critical revision. Khairul Azmi Abdul Kadir: substantial contributions to the conception or design of the work, critical revision.

Mei-Ling Sharon Tai: substantial contributions to the conception or design of the work, critical revision.

Kay Sin Tan: substantial contributions to the conception or design of the work, analysis, or interpretation of data for the work, critical revision, final approval.

\section{References}

1 Saver JL, Goyal M, van der Lugt A, Menon BK, Majoie CB, Dippel DW, et al.; HERMES Collaborators. Time to treatment with endovascular thrombectomy and outcomes from ischemic stroke: a meta-analysis. JAMA. 2016 Sep;316(12):1279-88.

2 Berkhemer OA, Fransen PS, Beumer D, van den Berg LA, Lingsma HF, Yoo AJ, et al.; MR CLEAN Investigators. A randomized trial of intraarterial treatment for acute ischemic stroke. N Engl J Med. 2015 Jan;372(1):1120.

3 Jovin TG, Chamorro A, Cobo E, de Miquel MA, Molina CA, Rovira A, et al.; REVASCAT Trial Investigators. Thrombectomy within 8 hours after symptom onset in ischemic stroke. N Engl J Med. 2015 Jun;372(24):2296-306.

4 Sheth KN, Terry JB, Nogueira RG, Horev A, Nguyen TN, Fong AK, et al. Advanced modality imaging evaluation in acute ischemic stroke may lead to delayed endovascular reperfusion therapy without improvement in clinical outcomes. J Neurointerv Surg. 2013 May;5 Suppl 1:i62-5.

5 Powers WJ, Rabinstein AA, Ackerson T, Adeoye OM, Bambakidis NC, Becker K, et al.; American Heart Association Stroke Council. 2018 guidelines for the early management of patients with acute ischemic stroke: a guideline for healthcare professionals from the American Heart Association/American Stroke Association. Stroke. 2018 Mar;49(3):e46-110.

6 Stroke Foundation. Clinical Guidelines for Stroke Management. Melbourne, Australia; 2017.

7 Khatri P, Yeatts SD, Mazighi M, Broderick JP, Liebeskind DS, Demchuk AM, et al.; IMS III Trialists. Time to angiographic reperfusion and clinical outcome after acute ischaemic stroke: an analysis of data from the Interventional Management of Stroke (IMS III) phase 3 trial. Lancet Neurol. 2014 Jun;13(6):567-74.

8 Menon BK, Almekhlafi MA, Pereira VM, Gralla J, Bonafe A, Davalos A, et al.; STAR Study Investigators. Optimal workflow and process-based performance measures for endovascular therapy in acute ischemic stroke: analysis of the Solitaire FR thrombectomy for acute revascularization study. Stroke. 2014 Jul;45(7):2024-9.

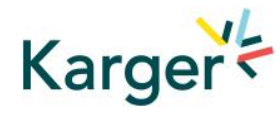




\section{Case Reports in Neurology}

\begin{tabular}{l|l}
\hline Case Rep Neurol 2020;12:15-21 \\
\hline DOI: 10.1159/000501820 & $\begin{array}{l}\text { @ 2020 The Author(s). Published by S. Karger AG, Basel } \\
\text { www.karger.com/crn }\end{array}$ \\
\hline
\end{tabular}

Toh et al.: Acute Stroke Thrombectomy with NCCT and CTA

9 Nogueira RG, Jadhav AP, Haussen DC, Bonafe A, Budzik RF, Bhuva P, et al.; DAWN Trial Investigators. Thrombectomy 6 to 24 hours after stroke with a mismatch between deficit and infarct. N Engl J Med. 2018 Jan;378(1):11-21.

10 Hill MD, Demchuk AM, Goyal M, Jovin TG, Foster LD, Tomsick TA, et al.; IMS3 Investigators. Alberta Stroke Program early computed tomography score to select patients for endovascular treatment: Interventional Management of Stroke (IMS)-III Trial. Stroke. 2014 Feb;45(2):444-9.

11 Gupta AC, Schaefer PW, Chaudhry ZA, Leslie-Mazwi TM, Chandra RV, González RG, et al. Interobserver reliability of baseline noncontrast CT Alberta Stroke Program Early CT Score for intra-arterial stroke treatment selection. AJNR Am J Neuroradiol. 2012 Jun;33(6):1046-9.

12 Broocks G, Hanning U, Flottmann F, Schönfeld M, Faizy TD, Sporns P, et al. Clinical benefit of thrombectomy in stroke patients with low ASPECTS is mediated by oedema reduction. Brain. 2019 May;142(5):1399-407.

13 Pierot L, Soize S, Benaissa A, Wakhloo AK. Techniques for endovascular treatment of acute ischemic stroke: from intra-arterial fibrinolytics to stent-retrievers. Stroke. 2015 Mar;46(3):909-14.

14 Fischer U, Kaesmacher J, Mendes Pereira V, Chapot R, Siddiqui AH, Froehler MT, et al. Direct mechanical thrombectomy versus combined intravenous and mechanical thrombectomy in large-artery anterior circulation stroke: a topical review. Stroke. 2017 Oct;48(10):2912-8.

15 Mistry EA, Mistry AM, Nakawah MO, Chitale RV, James RF, Volpi JJ, et al. Mechanical thrombectomy outcomes with and without intravenous thrombolysis in stroke patients: a meta-analysis. Stroke. 2017 Sep;48(9):2450-6.

16 Seners P, Turc G, Maïer B, Mas JL, Oppenheim C, Baron JC. Incidence and predictors of early recanalization after intravenous thrombolysis: a systematic review and meta-analysis. Stroke. 2016 Sep;47(9):2409-12.

17 Santos T, Carvalho A, Cunha AA, Rodrigues M, Gregório T, Paredes L, et al. NCCT and CTA-based imaging protocol for endovascular treatment selection in late presenting or wake-up strokes. J Neurointerv Surg. 2019 Feb;11(2):200-3.
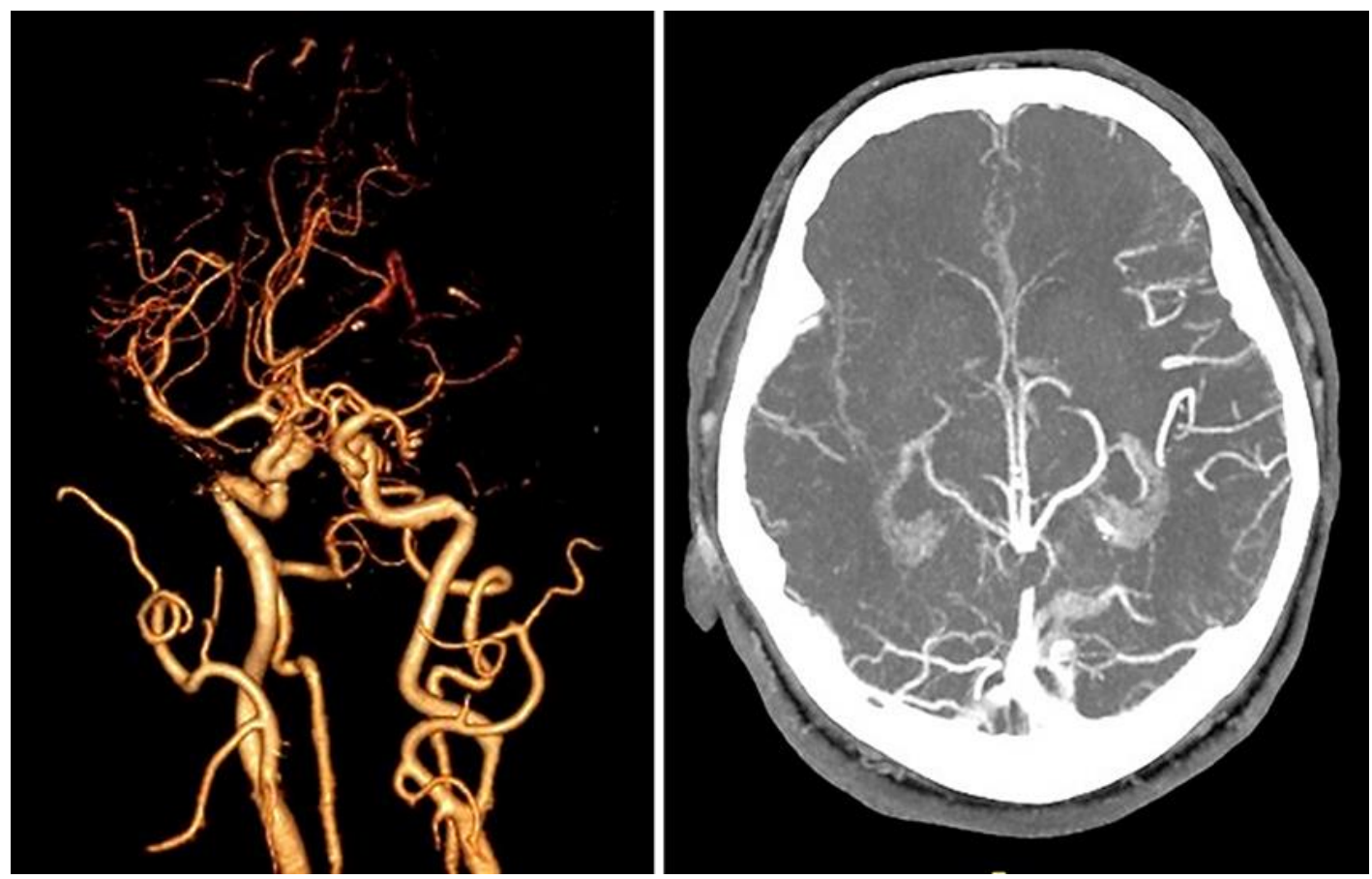

Fig. 1. CT angiogram shows complete occlusion of the left distal M1 segment with increased collateral over the left M2 territory. 
Case Reports in Neurology
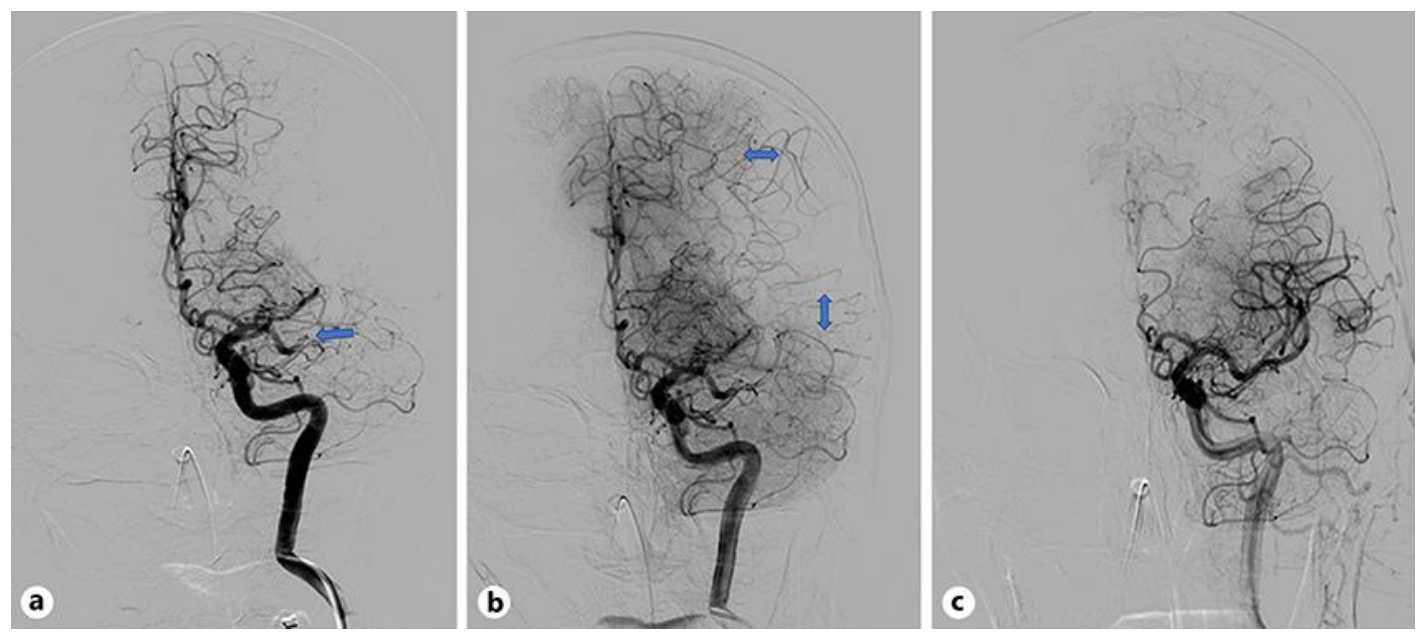

Fig. 2. a There is complete occlusion of the left distal M1 segment on angiogram (blue arrow). b Pial-to-pial collaterals (blue arrow) seen from the left ACA and left PCA supplying the left MCA in the delayed phase of cerebral angiogram. c Post-thrombectomy shows TICI $2 b$ reperfusion of the left MCA. 